\title{
Rifabutin-Loaded Nanostructured Lipid Carriers as a Tool in Oral Anti-Mycobacterial Treatment of Crohn's Disease
}

\author{
Helena Rouco ${ }^{1}$, Patricia Diaz-Rodriguez ${ }^{2}{ }^{\circledR}$, Diana P. Gaspar ${ }^{3}$, Lídia M. D. Gonçalves ${ }^{3}{ }^{\circledR}$, \\ Miguel Cuerva $\left.{ }^{4}{ }^{(}\right)$, Carmen Remuñán-López ${ }^{5}$, António J. Almeida ${ }^{3}\left[\right.$ and Mariana Landin ${ }^{1, *} \mathbb{C}$ \\ 1 R+D Pharma Group (GI-1645), Strategic Grouping in Materials (AEMAT), Department of Pharmacology, \\ Pharmacy and Pharmaceutical Technology, Faculty of Pharmacy, Universidade de Santiago de \\ Compostela-Campus Vida, 15782 Santiago de Compostela, Spain; helena.rouco@rai.usc.es \\ 2 Drug Delivery Systems Group, Department of Chemical Engineering and Pharmaceutical Technology, \\ School of Sciences, Universidad de La Laguna (ULL), Campus de Anchieta, 38200 La Laguna (Tenerife), \\ Spain; pdiarodr@ull.edu.es \\ 3 Research Institute for Medicines (iMed.ULisboa), Faculty of Pharmacy, Universidade de Lisboa, \\ 1649-003 Lisbon, Portugal; diana.gaspar89@gmail.com (D.P.G.); lgoncalves@ff.ulisboa.pt (L.M.D.G.); \\ aalmeida@ff.ulisboa.pt (A.J.A.) \\ 4 Department of Physical Chemistry, Nanomag laboratory, Universidade de Santiago de Compostela-Campus \\ Vida, 15782 Santiago de Compostela, Spain; miguelcvidales@gmail.com \\ 5 Nanobiofar Group (GI-1643), Department of Pharmacology, Pharmacy and Pharmaceutical Technology, \\ Faculty of Pharmacy, Universidade de Santiago de Compostela-Campus Vida, \\ 15782 Santiago de Compostela, Spain; mdelcarmen.remunan@usc.es \\ * Correspondence: m.landin@usc.es
}

Received: 29 September 2020; Accepted: 26 October 2020; Published: 27 October 2020

check for updates

\begin{abstract}
Oral anti-mycobacterial treatment of Crohn's disease (CD) is limited by the low aqueous solubility of drugs, along with the altered gut conditions of patients, making uncommon their clinical use. Hence, the aim of the present work is focused on the in vitro evaluation of rifabutin (RFB)-loaded Nanostructured lipid carriers (NLC), in order to solve limitations associated to this therapeutic approach. RFB-loaded NLC were prepared by hot homogenization and characterized in terms of size, polydispersity, surface charge, morphology, thermal stability, and drug payload and release. Permeability across Caco-2 cell monolayers and cytotoxicity and uptake in human macrophages was also determined. NLC obtained were nano-sized, monodisperse, negatively charged, and spheroidal-shaped, showing a suitable drug payload and thermal stability. Furthermore, the permeability profile, macrophage uptake and selective intracellular release of RFB-loaded NLC, guarantee an effective drug dose administration to cells. Outcomes suggest that rifabutin-loaded NLC constitute a promising strategy to improve oral anti-mycobacterial therapy in Crohn's disease.
\end{abstract}

Keywords: rifabutin; nanostructured lipid carriers; cell uptake; Caco-2 cells; oral administration; Crohn's disease

\section{Introduction}

Crohn's disease (CD) is a chronic inflammatory bowel condition with a higher predominance in industrialized countries, principally in Western Europe and North America [1]. The disease is characterized by the presence of outbreaks followed by remission periods [1,2], and although symptomatology is variable, diarrhea, abdominal pain, nausea, vomiting, and weight loss are usually involved [1]. The inflammatory process is usually transmural, involving any region of the digestive tract, affecting distal ileum and colon mainly $[1,2]$. 
CD aetiology has been a controversial topic recently [3]. Disease development is currently associated with genetic susceptibility and environmental factors, such as alterations in gut microbiome and treatment with antibiotics or non-steroidal anti-inflammatories [1,2]. Nevertheless, it is necessary to highlight the recent increment in scientific literature showing the contribution of the mycobacterial pathogen Mycobacterium avium paratuberculosis (MAP) in CD instauration [3,4]. Moreover, inflamed mucosal and submucosal layers in CD are infiltrated by immune cells such as macrophages [5]. These cells constitute an interesting target for anti-mycobacterial therapy, since MAP is a facultative intracellular organism that resides in host macrophages, establishing a persistent infection [6].

Despite this information, CD's current treatment is still focused on the pharmacological control of the inflammatory process (using immunosuppressants, corticosteroids, anti-TNF or anti-interleukin drugs and adhesion molecule inhibitors) with the main objective of maintaining the disease remission stage without the need for surgery [1]. However, although these treatments improve patients' quality of life, their ability to modify the long-term evolution of the disease has not been demonstrated yet [2].

Regarding the antibiotic use in CD, they are nowadays relegated to the treatment of perianal fistulas or disease suppurative complications [1]. Still, some case reports describe long-term CD remissions after antibiotic therapy [4]. Moreover, an open label extension phase III study sponsored by RedHill Biopharma is currently actively testing orally administered capsules containing a combination of rifabutin, clofazimine and clarithromycin at fixed doses in CD patients [7]. This study includes the introduction of a MAP PCR test at the baseline and the evaluation of changes of this blood status during the study [7], which would give insight into in vivo effectivity of this antibiotic combination [8] and into the clinical benefit derived from MAP eradication [9].

Although orally administered antimycobacterial drugs constitute a promising strategy in CD treatment, two aspects limit this approach. First, gut physiological parameters are altered in CD patients, which can reduce the possibilities to exploit $\mathrm{pH}$, transit time or microbiome as targeting strategies for drug delivery [5]. On the other hand, antimycobacterial drugs show high lipophilicity and low oral bioavailability [10-12].

In this context, particulate systems constitute an interesting approach, as they can accumulate in inflamed bowel sites [5]. Additionally, nanoparticulated systems can be designed to load lipophilic drugs, improving their oral bioavailability $[13,14]$. Moreover, the drug particle reduction to nano size can lead to an enhanced water solubility and dissolution rate [15].

Among nanoparticulate systems, Nanostructured Lipid Carriers (NLC), the second generation of lipid nanoparticles (LN) [16], can be good candidates to formulate useful antimycobacterial systems. NLC are solid matrices at both room and body temperatures [17]. They are composed by a solid lipid and a liquid lipid [16] and present several advantages over the first generation of LN (known as Solid Lipid Nanoparticles or SLN), such as improved stability, higher suppleness in drug release modulation, and increased drug loading capacity [17]. NLC "in vitro" tolerability seems to be higher in comparison with other colloidal carriers, such as polymeric nanoparticles [18], making them an interesting option for oral drug administration.

Therefore, the aim of this work is to investigate the performance of rifabutin (RFB)-loaded NLC (whose formulation procedure and composition were previously optimized by Artificial Intelligence tools), to demonstrate their safety and suitability to achieve an appropriate intestinal permeability and an efficient macrophages uptake. Our goal is to improve the current Crohn's disease treatments intended to eradicate MAP housed within intestinal macrophages, an area in which, to the best of our knowledge, nanotechnology has never been applied. In this way, an extensive characterization of the nanosystems in terms of particle size, polydispersity, surface charge, and drug payload, was performed. Thermal resistance, morphology, and drug release from NLC in different simulated media were also evaluated. Furthermore, an analysis of the in vitro performance of NLC in cell cultures including a permeability evaluation through Caco-2 monolayers, along with the assessment of cytotoxicity and uptake in human macrophages, was carried out in order to evaluate the targeting potential of the developed nanocarriers. 


\section{Materials and Methods}

\subsection{Materials}

Rifabutin (RFB) (98\% purity) was purchased from Acros Organics ${ }^{\mathrm{TM}}$ (Fair Lawn, NJ, USA). Polysorbate 80 (Tween ${ }^{\circledR}$ 80), Coumarin 6, dialysis membrane (Spectrum ${ }^{\mathrm{TM}}$ Labs Spectra/Por, MWCO 3.5 KDa), and phorbol 12-myristate 13-acetate (PMA) were acquired from Sigma Aldrich (St Louis, MO, USA). Oleic acid was obtained from Merck (Darmstadt, Germany). Precirol ${ }^{\circledR}$ ATO 5 (glyceryl distearate) and Epikuron ${ }^{\circledR} 145 \mathrm{~V}$ (deoiled phosphatidyl choline-enriched lecithin) were kind gifts from Gattefossé (Saint-Priest, France) and Cargill (Wayzata, MN, USA) respectively. THP-1, Caco-2 human colon carcinoma and RAW 264.7 cell lines were obtained from ATCC (Manassas, VA, USA). Alexa Fluor ${ }^{\mathrm{TM}} 647$ phalloidin, ProLong ${ }^{\circledR}$ Gold Antifade reagent with DAPI, Gibco ${ }^{\mathrm{TM}}$ antibiotic-antimycotic (amphotericin B, penicillin, streptomycin), trypsin-EDTA, foetal bovine serum (FBS), Roswell Park Memorial Institute 1640 Medium (RPMI 1640), Minimum Essential Media ( $\alpha$-MEM), and phosphate buffered saline (PBS) were obtained from Thermo Fisher Scientific (Waltham, MA, USA). Dulbeco's Modified Eagle Medium (DMEM) was purchased from Corning (Corning, NY, USA). Antibiotic solution (10.000 units/mL penicillin, $10.000 \mu \mathrm{g} / \mathrm{mL}$ streptomycin) was acquired from GE Healthcare Life Sciences (Chicago, IL, USA). Cell proliferation kit (WST-1) was purchased from Roche (Basel, Switzerland). Ultrapure water (MilliQ plus, Millipore Ibérica, Madrid, Spain) was used throughout and the remaining solvents and reagents were analytical or HPLC grade.

\subsection{NLC Formulation}

Several batches of NLC loaded with RFB were developed utilizing the composition and operating conditions of a previously optimized NLC system using Artificial Intelligence tools [19]. Briefly, the components of the formulation were Precirol ${ }^{\circledR}$ ATO 5 and oleic acid as the lipid components (25:75 ratio), and Tween ${ }^{\circledR} 80$ and Epikuron ${ }^{\circledR} 145 \mathrm{~V}$ as surfactants. The drug (15 mg) was dissolved in the molten lipid phase at $80{ }^{\circ} \mathrm{C}(300 \mathrm{mg})$. The aqueous phase $(10 \mathrm{~mL})$, a dispersion of Epikuron ${ }^{\circledR}$ $145 \mathrm{~V}\left(0.5 \% w / w\right.$ regarding the lipid phase weight) and Tween ${ }^{\circledR} 80(1.9 \% w / v$ regarding aqueous phase) in Milli- $\mathrm{Q}^{\circledR}$ water, was heated at the same temperature, added to the lipid phase and hot shear homogenized $\left(80^{\circ} \mathrm{C}\right.$ ) using an Ultra-Turrax T25 (IKA Labortechnik, Staufen, Germany) at 14,800 rpm for $10 \mathrm{~min}$, in a water bath. NLC dispersions were rapidly cooled by transferring them to an ice bath, with gentle stirring, for $2 \mathrm{~min}$. Formulations were carried out in quintuplicate and subsequently dialyzed overnight (MWCO 3.5 KDa), in order to remove the non-incorporated components and obtain the purified NLC.

\subsection{NLC Characterization}

\subsubsection{Particle Size, Surface Charge and Physical Stability}

Particle size, polydispersity index and surface charge of NLC were determined using a Zetasizer Nano ZS (Malvern Instruments, Malvern, UK). For size and polydispersity index determinations, samples were placed in polystyrene cuvettes and diluted with Milli- $Q^{\circledR}$ water (1:10). Surface charge was determined as zeta potential through particle mobility in an electric field. To carry out this determination, samples were also diluted with Milli- $\mathrm{Q}^{\circledR}$ water (1:10) and placed in a specific cuvette where a potential of $\pm 150 \mathrm{mV}$ was established. All the measurements were performed at $25 \pm 1{ }^{\circ} \mathrm{C}$ by quadruplicate.

\subsubsection{Transmission Electron Microscopy (TEM)}

Transmission electron microscopy was employed to evaluate morphology of blank (control NLC without drug) and RFB-loaded NLC and to confirm particle sizes previously obtained by DLS. Thus, NLC suspensions were placed on formvar/carbon-coated grids (400 mesh) and stained with $2 \%(w / v)$ uranyl acetate. Finally, samples were analysed using a JEOL microscope (JEM 1010, Tokyo, Japan). 
Images were then obtained by using a CCD Orius-Digital Montage Plug-in camera (Gatan, Inc., Pleasanton, CA, USA) and analysed by means of a Gatan Digital Micrograph software (Gatan, Inc., USA). The number of particles considered for size determinations were 44 and 12 for blank and loaded NLC, respectively.

\subsubsection{Atomic Force Microscopy (AFM)}

NLC morphology, particle size and size distribution were also analysed by atomic force microscopy (AFM). This technique is based on the electrostatic interaction between the sample and the AFM tip, which allows for the determination of a sample topography. Measurements were conducted under normal ambient conditions using an XE-100 instrument (Park Systems, Suwon, South Korea) in non-contact mode with the high-resonance non-contact AFM cantilever (ACTA probe, $\mathrm{n}=330 \mathrm{kHz}$ ). For AFM imaging, $20 \mu \mathrm{L}$ of the sample were dropped onto freshly exfoliated mica sheet (SPI Supplies, grade V-1 Muscovite) and after 5 min the mica was washed with Milli-Q water and dried under nitrogen flow. All experiments were performed at room temperature. XEI ${ }^{\circledR}$ data processing tool (Park Systems, South Korea) were used for the analysis of the obtained data, which were adjusted to a gaussian distribution.

\subsubsection{Encapsulation Efficiency and Drug Loading}

Encapsulation efficiency and drug loading determinations were performed as previously described [19]. Purified NLC and non-purified NLC (200 $\mu$ L) were dissolved with acetonitrile $(1.5 \mathrm{~mL})$ and centrifuged at $16,099 \times g$ and $4{ }^{\circ} \mathrm{C}$ for $30 \mathrm{~min}$. Centrifugation produces the precipitation of the lipid phase, while the drug remains in the supernatant. RFB quantification was performed by High Performance Liquid Chromatography (HPLC) as described in Section 2.4. The amount of drug quantified in the supernatant of non-purified nanoparticles was used as total drug content.

Encapsulation efficiency (EE) and drug loading (DL) of NLC were calculated using the following equations:

$$
\begin{gathered}
\mathrm{EE}(\%)=\left[\left(\mathrm{W}_{\text {loaded drug }}\right) / \mathrm{W}_{\text {total drug }}\right] \times 100, \\
\mathrm{DL}(\%)=\left[\left(\mathrm{W}_{\text {loaded drug }}\right) / \mathrm{W}_{\text {lipid }}\right] \times 100,
\end{gathered}
$$

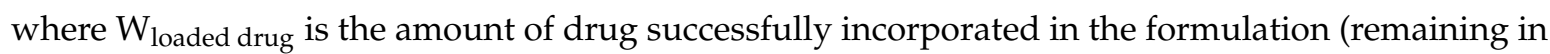
the supernatant following acetonitrile addition), $W_{\text {total drug }}$ is the total amount of drug, and $W_{\text {lipid }}$ is the weight of the lipid vehicle.

\subsubsection{Thermal Analysis Using Dynamic Light Scattering (DLS)}

The influence of temperature on both blank and RFB-loaded NLC suspensions stability was analysed by DLS in a Zetasizer Nano ZS. Three batches of each type of NLC (blank and loaded with RFB) were diluted as described above, and particle size measurements were made during heating and cooling cycles $\left(25^{\circ} \mathrm{C}-90^{\circ} \mathrm{C}-25^{\circ} \mathrm{C}\right)$ at $0.5^{\circ} \mathrm{C} / \mathrm{min}$ in quartz cells. Particle size determinations were recorded every $0.5^{\circ} \mathrm{C}$. Each batch was analysed in duplicate.

\subsubsection{In Vitro Release Studies}

RFB release from loaded NLC was investigated in simulated intestinal fluid (SIF) and macrophage's lysate, in order to compare NLC behaviour in different environments, the intestinal tract and inside macrophages. SIF with pancreatin was prepared according to United States Pharmacopeia (USP).

In order to obtain macrophages cell lysate, Raw 264.7 cells (a murine macrophage cell line) were cultured in DMEM supplemented with 10\% foetal bovine serum (FBS) and 1\% penicillin/streptomycin and incubated at $37{ }^{\circ} \mathrm{C}$ and $5 \% \mathrm{CO}_{2}$. Cells were split when reaching $80 \%$ confluence by trypsinization and expanded until achieving enough number of cells. Cells were then trypsinized using standard conditions, washed with PBS, centrifuged, and resuspended in Milli- $\mathrm{Q}^{\circledR}$ water in order to achieve a 
concentration of 3.125 million cells $/ \mathrm{mL}$. Cell lysis was performed by subjecting the cell suspension to three freeze-thaw cycles.

Drug release studies were performed by quadruplicate at $37^{\circ} \mathrm{C}$ in horizontal Franz diffusion cells, where a 1:3 dilution of the nanoparticle suspension in release medium was put in the donor chamber. A dialysis membrane (MWCO $3.5 \mathrm{KDa}$ ) was placed between the two chambers in order to avoid the presence of NLC in the receptor chamber. At pre-set times, samples were taken from the receptor chamber and replaced with fresh medium. Drug quantification was performed by HPLC.

\subsection{High Performance Liquid Chromatography Method}

RFB was quantified following a validated method previously described [20], using an Agilent 1100 HPLC system (Agilent Technologies, Santa Clara, CA, USA) equipped with a C18 column (Waters symmetry $5 \mu \mathrm{m}, 3.9 \times 150 \mathrm{~mm}$ ). Throughout HPLC analysis, $20 \mu \mathrm{L}$ of each sample were injected and eluted with a mobile phase composed by a mixture of sodium acetate $0.05 \mathrm{M} /$ potassium dihydrogen phosphate $0.05 \mathrm{M}$ (pH adjusted to 4.0 with acetic acid) and acetonitrile (Scharlau, Barcelona, Spain) in a 53:47 (v/v) proportion. Drug quantification was performed at $275 \mathrm{~nm}$, with a $1 \mathrm{~mL} / \mathrm{min}$ flow rate in an isocratic mode.

\subsection{In Vitro Cell Studies}

\subsubsection{Cell Viability Studies}

Cytotoxicity of NLC formulations was analysed using WST-1 (2-(4-iodophenyl)-3-(4-nitrophenyl)-5-(2,4-disulfophenyl)-2H tetrazolium, monosodium salt; Roche, Indianapolis, IN, USA), which produces a water-soluble formazan dye upon cellular reduction by the mitochondrial succinate-tetrazolium reductase [21,22]. Human monocytes (THP-1) were cultured in RPMI 1640 supplemented with 10\% heat-inactivated foetal bovine serum (FBS), $1 \%$ penicillin/streptomycin and 2-mercaptoethanol $0.05 \mathrm{mM}$ at $37^{\circ} \mathrm{C}$ and $5 \% \mathrm{CO}_{2}$. Five days before the experiment, cells were differentiated to macrophages by stimulation with $200 \mathrm{nM}$ of PMA (Phorbol 12-myristate 13-acetate) for 3 days at a cell density of $2 \times 10^{5} \mathrm{cells} / \mathrm{mL}$. Then, PMA-containing medium was replaced by fresh medium and cells were incubated for another 2 days with normal media. The day before the experiment, cells were seeded at a density of $2.5 \times 10^{4}$ cells/well in 96-well plates. Purified NLC samples were diluted to achieve a final concentration of $0.3,0.12,0.06$, and $0.03 \mathrm{mg} / \mathrm{mL}$ of nanoparticles solid mass per volume. To evaluate cell viability, macrophages were incubated with blank and RFB-loaded NLC formulations, as well as with RFB solutions (concentration equivalent to those present in the previous NLC dilutions), for $24 \mathrm{~h}\left(37^{\circ} \mathrm{C}, 5 \% \mathrm{CO}_{2}\right)$. After the incubation period, samples were removed and $10 \mu \mathrm{L}$ of WST-1 reagent along with $100 \mu \mathrm{L}$ of culture medium were added to each well. After $2 \mathrm{~h}$ of incubation with WST-1 reagent, absorbance was read at $450 \mathrm{~nm}$ in a microplate reader (Model 680, Bio-Rad, Hercules, CA, USA). Cell viability relative to negative control (Milli- ${ }^{\circledR}$ water or DMSO, as appropriate) was calculated according to the following equation:

$$
\text { Cell viability }(\%)=(\text { Sample Absorbance/Control Absorbance }) \times 100 \text {, }
$$

\subsubsection{Confocal Microscopy}

Qualitative analysis of NLC internalization by THP-1 derived macrophages was performed by confocal microscopy. For this purpose, nanoparticles were fluorescently labelled with coumarin 6 by incorporating the fluorophore into the oil phase during the formulation process. Cells were seeded at a concentration of $5.3 \times 10^{4}$ cells $/ \mathrm{cm}^{2}$ in chambered cell culture slides (Nunc ${ }^{\mathrm{TM}}$ Lab-Tek II Chamber Slide ${ }^{\mathrm{TM}}$, Thermo Fisher Scientific, Waltham, MA, USA) the day before the experiment. Then, cells were incubated at $37^{\circ} \mathrm{C}$ and $5 \% \mathrm{CO}_{2}$ for $5 \mathrm{~h}$ with the samples (blank and RFB-loaded NLC), which were added in a final concentration of $0.12 \mathrm{mg} / \mathrm{mL}$. After this incubation period, culture medium was removed, and cells were washed twice with pre-warmed phosphate buffered saline (PBS). Cell fixation 
was performed using a 3.7\% formaldehyde solution in PBS for $10 \mathrm{~min}$ at room temperature, followed by two washing steps with PBS. Then, a $0.1 \%$ Triton X-100 solution was added to permeabilize the cell membrane. Finally, cells were incubated with a 1:40 dilution of Alexa Fluor ${ }^{\mathrm{TM}} 647$ phalloidin in PBS for $20 \mathrm{~min}$ in order to label the macrophages cytoskeleton, and after two extra washing steps, macrophages nucleus were stained with ProLong ${ }^{\circledR}$ Gold Antifade reagent with DAPI. Images were obtained using a confocal laser microscopy Leica SP5 (Leica Microsystems, Wetzlar, Germany).

\subsubsection{Macrophage Uptake Quantification}

To quantify NLC uptake by THP-1 derived macrophages, NLC were fluorescently labelled with coumarin 6 as previously described. Dialysis of the samples was also accomplished prior to performing the experiment. Macrophage uptake quantification was carried out according to a method previously described [23] with slight modifications. First, macrophages were seeded in 96-well plates at a cell density of $2.5 \times 10^{5}$ cells $/ \mathrm{mL}$ and $100 \mu \mathrm{L}$ per well; nanoparticle suspensions were added to them at a final concentration of $0.12 \mathrm{mg} / \mathrm{mL}$, and fluorescence was determined in a microplate reader (Fluostar Optima, BMG Labtech, Offenburg, Germany) at an excitation and emission wavelength of 485 and $520 \mathrm{~nm}$, respectively (Initial fluorescence). Cells were then incubated during $2 \mathrm{~h}$ at $37{ }^{\circ} \mathrm{C}$ and $5 \%$ $\mathrm{CO}_{2}$. Samples were removed, and cells were subjected to three washing steps with $250 \mu \mathrm{L}$ of a $20 \mathrm{mM}$ glycine solution in PBS pH 7.4, in order to remove non-internalized nanoparticles and to quench their fluorescent signals. Finally, $100 \mu \mathrm{L}$ of Triton X-100 1\% were added to disrupt cellular membrane, and fluorescence was again measured (Fluorescence post-lysis). Macrophage uptake was calculated according to the following equation:

$$
\text { Macrophage uptake }(\%)=(\text { Fluorescence post-lysis/Initial fluorescence }) \times 100,
$$

\subsubsection{Nanoparticle Permeation across Caco-2 Cells Monolayers}

Permeation studies were performed in human colon carcinoma Caco-2 cell line according to a previously described protocol [24], with modifications. Cells were seeded at a concentration of $6.25 \times 10^{3}$ cells $/ \mathrm{cm}^{2}$ in Corning ${ }^{\circledR}$ Transwell ${ }^{\circledR}$ polycarbonate membrane cell culture inserts (Corning, Corning, NY, USA) and cultured in $\alpha$-MEM supplemented with 20\% FBS, $1 \%$ penicillin/streptomycin and $1 \%$ antibiotic/antimycotic. Culture medium was replaced every $3-4$ days and cells were incubated at $37^{\circ} \mathrm{C}$ and $5 \% \mathrm{CO}_{2}$ for 28 days, approximately, until the monolayer reached a suitable transepithelial electrical resistance (TEER). At the beginning of the experiment, TEER was higher than $400 \Omega \mathrm{cm}^{2}$, which indicates the formation of an intact monolayer [24].

RFB-loaded NLC fluorescently labelled with coumarin 6 at a final concentration of $0.12 \mathrm{mg} / \mathrm{mL}$ or pure Milli- $\mathrm{Q}^{\circledR}$ water (control), were added in the donor compartment. After 2, 4, 6, 24, and $48 \mathrm{~h}$, samples were taken from the receptor compartment and replaced by fresh medium. Fluorescence was measured in a microplate reader (Fluostar Optima, BMG Labtech, Germany), as previously described, in order to evaluate NLC passage across the cell monolayer. Moreover, in order to correlate the amount of NLC present in the receptor compartment with the fluorescent signal obtained, a calibration curve was prepared in triplicate by measuring the fluorescence of known amounts of coumarin 6-labelled RFB-loaded NLC. Finally, permeability of NLC across Caco-2 cells was expressed either as the concentration of permeated RFB $(\mu \mathrm{g} / \mathrm{mL})$ regarding time elapsed or as a function of the apparent permeability coefficient $\left(\mathrm{P}_{\mathrm{app}}\right)$, which is employed to investigate the transport rate. $\mathrm{P}_{\text {app }}$ was determined according to the following equation:

$$
\operatorname{Papp}(\mathrm{cm} / \mathrm{s})=\mathrm{dQ} / \mathrm{dt} \times 1 /\left(\mathrm{A} \times \mathrm{C}_{0}\right)
$$

where $C_{0}$ is the initial RFB concentration in the upper compartment $(6 \mu \mathrm{g} / \mathrm{mL}), A$ is the growth area $\left(0.33 \mathrm{~cm}^{2}\right)$ and $\mathrm{dQ} / \mathrm{dt}$ is the appearance rate of the particles on the lower chamber based on its 
cumulative transport for $48 \mathrm{~h}$. This linear appearance rate was calculated as the slope resulting from the representation of the RFB amount present in the receptor compartment versus time.

\subsection{Statistical Analysis}

All experiments were performed at least in triplicate. The data were expressed by mean \pm SD and treated with IBM SPSS 24 software. The confidence interval was $95 \%(p \leq 0.05)$. The groups were compared by performing one-way or two-way analysis of variance (ANOVA), as appropriate, followed by post hoc Tukey's Multiple Comparison Test, and the significant differences between groups were determined.

\section{Results and Discussion}

\subsection{NLC Characterization}

NLC formulation procedure and composition were beforehand optimized by Artificial Intelligence (AI) tools in order to achieve optimal physicochemical properties along with a suitable drug payload [19]. Stability of the developed nanocarriers has proven to be adequate after 1 month of storage at $5 \pm 1^{\circ} \mathrm{C}$, in terms of particle size, polydispersity index and drug payload. Minor changes without impact over colloidal stability were found for zeta potential [19]. Besides, an estimation of the characteristics of RFB-loaded NLC, prepared with these optimized parameters, was also provided [19]. In this way, to verify the robustness of this optimizations process, RFB-loaded NLC were prepared, and particle size, PDI, ZP, and drug payload were again determined. Furthermore, this work includes further characterization of these nanocarriers in terms of morphology, thermal behaviour, release profile, and in vitro performance in cell cultures.

\subsubsection{Particle Size, Surface Charge, Physical Stability, and Drug Payload}

Blank and RFB-loaded NLC were prepared using hot high shear homogenization. Formulations were carried out in quintuplicate, dialyzed overnight and fully characterized in terms of particle size, size distribution, surface charge, and drug load (Table 1).

Table 1. Blank and RFB-loaded NLC characterization in terms of particle size, PDI, ZP, EE, and DL $(\mathrm{n}=3 \pm \mathrm{SD})$.

\begin{tabular}{cccccc}
\hline NLC & Size $(\mathbf{n m})$ & PDI & ZP (mV) & EE (\%) & DL (\%) \\
\hline Blank & $111 \pm 3$ & $0.23 \pm 0$ & $-26 \pm 2$ & - & - \\
RFB-loaded & $151 \pm 34$ & $0.22 \pm 0.02$ & $-24 \pm 2$ & $92.83 \pm 3.75$ & $4.62 \pm 0.33$ \\
\hline
\end{tabular}

Particle size and size distribution are known to affect NLC characteristics such as stability, release rate and biologic performance [17], and because of that, they should be carefully characterized. NLC formulations showed particle sizes within the nano range, with values of $111 \pm 3 \mathrm{~nm}$ and $151 \pm 34 \mathrm{~nm}$, for blank and RFB-loaded nanocarriers, respectively. Differences in size observed between blank and loaded formulations could be associated with the required accommodation space for the drug [25]. Regarding particle size distribution, blank NLC showed a polydispersity index (PDI) value of $0.23 \pm 0.00$, whereas the loaded ones displayed an almost identical value of $0.22 \pm 0.02$. Therefore, the obtained PDI values were below 0.3 in both cases, which is an acceptable value for lipid nanocarriers and indicative of homogeneous particle size distribution [26]. Remarkably, both size and PDI values obtained for RFB-loaded NLC are in close agreement with those previously predicted by Artificial Intelligence tools, which have been reported to be $152 \mathrm{~nm}$ and 0.23, for size and PDI, respectively [19].

Moreover, both blank and loaded nanocarriers showed zeta potential values close to $-25 \mathrm{mV}$ (-26 \pm 2 and $-24 \pm 2 \mathrm{mV}$, for blank and RFB-loaded NLC, respectively), which guarantees a good colloidal stability if emulsifiers are included among formulation components [17,27]. These results differ slightly from those predicted by Artificial Intelligence tools, which showed slightly less negative 
values $(-19 \mathrm{mV})$ [19]. However, these differences in ZP could be easily associated with the dialysis step performed in this work after NLC formulation, which can favour the removal of NLC superficial components, such as Tween ${ }^{\circledR} 80$, a non-ionic emulsifier. Since this type of emulsifier has been reported to localize close to the nanoparticle interface, counteracting the negative charge of the lipid matrix [28], its partial removal is expected to lead to a more negative zeta potential. Furthermore, these small differences could only have a slight impact on colloidal stability and are not likely to influence the in vivo fate of the nano-formulations.

Concerning drug payload, RFB was incorporated to NLC at $5 \%(w / w)$ regarding lipid matrix weight showing a suitable drug payload, with an encapsulation efficiency (EE) of $92.83 \pm 3.75 \%$ and a drug loading (DL) of $4.62 \pm 0.33 \%$. These values suggest that almost all the added drug was successfully incorporated into the nanoparticle matrix. In the same way as in the case of particle size and PDI, EE and DL values obtained are almost identical to those predicted by Artificial intelligence tools, which have been reported to exhibit values of $100 \%$ and $5 \%$, for EE and DL, respectively [19].

Hence, the NLC physicochemical characterization data show that they have a particle size within the nano-range, a monodisperse particle size distribution and a suitable drug payload. Besides, the highly negative zeta potential exhibited by the formulations is expected to promote a good colloidal stability. Finally, the results of RFB-loaded NLC characterization closely agree with those predicted by Artificial Intelligence, demonstrating the suitability of these tools to successfully optimize the design of nanoparticle-based drug delivery systems and develop robust and reproducible protocols of NLC preparation.

\subsubsection{Thermal Analysis Using Dynamic Light Scattering (DLS)}

To assess NLC thermal stability, blank and RFB-loaded formulations were subjected to a heating stage from $25^{\circ} \mathrm{C}$ to $90^{\circ} \mathrm{C}$, followed by a cooling step to the initial temperature. This approach was previously described to investigate the ability of lipid nanoparticle formulations to maintain their initial properties during high temperature-related procedures [23,29].

In the case of blank NLC (Figure 1A), particle size remains almost unchanged during the whole thermal analysis. A similar behavior was observed for RFB-loaded NLC (Figure 1B) but showing a slight reduction in nanoparticle size. Particle size maintenance along with the negligible size variations exhibited by both formulations throughout the assay indicate a good thermal stability. Therefore, results obtained suggest the developed NLC formulations are suitable for further temperature-requiring processes, as is the case of spray-drying [23], that could simplify the oral administration of NLC obtaining dried powders, which can be easily administered in capsules or tablets [30].

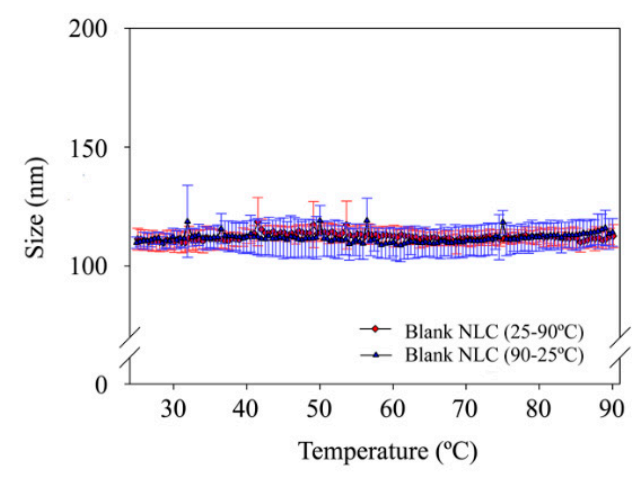

(A)

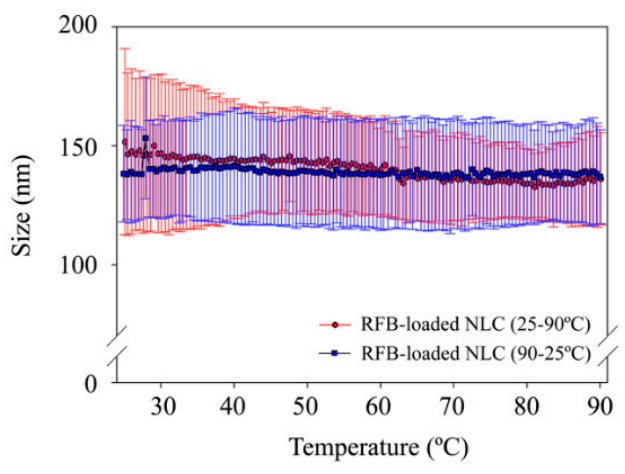

(B)

Figure 1. Dynamic light scattering thermograms of (A) Blank NLC formulations and (B) RFB-loaded NLC formulations. 


\subsubsection{Transmission Electron Microscopy (TEM)}

TEM technique was employed to evaluate both blank and RFB-loaded NLC morphology as well as to verify nanocarriers size, as recommended elsewhere [27]. As shown in Figure 2, NLC exhibit a spheroidal morphology. Furthermore, in some images (such as Figure 2B), a structure with concentric layers could be noticed, which is also disturbed towards the center of the nanoparticle, exhibiting a high electron density. This lipid nanoparticle structure has been previously described and is associated with the polymorphic $\alpha$-form of lipids [31]. Moreover, a size of $119 \pm 41 \mathrm{~nm}$ in the case of blank NLC and slightly higher $(173 \pm 85 \mathrm{~nm})$ in the case of RFB-loaded ones was observed, confirming the results obtained by DLS.

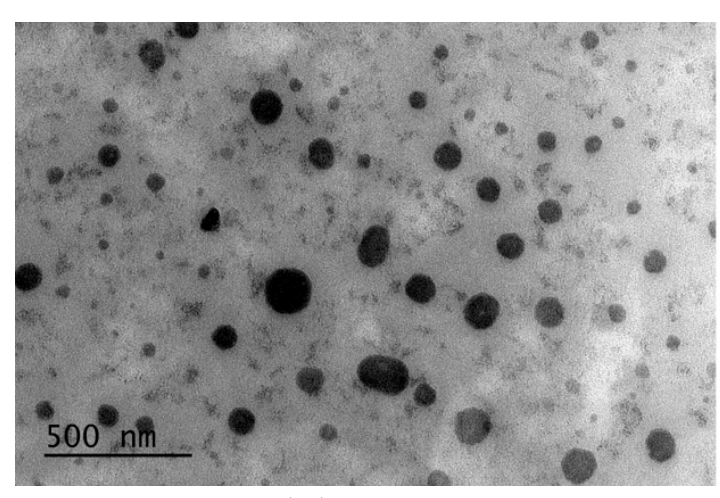

(A)

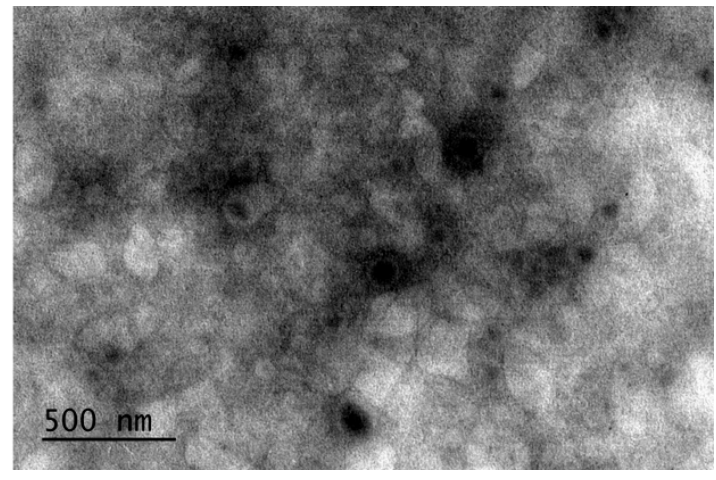

(B)

Figure 2. Transmission electron micrographs of (A) Blank and (B) RFB-loaded NLC.

\subsubsection{Atomic Force Microscopy (AFM)}

Blank and RFB-loaded NLC morphology, particle size and distribution were also assessed by Atomic force microscopy, a technique which gives insight into the sample z-dimension from the deflection of a fine leaf spring (known as the AFM cantilever) [32]. Therefore, AFM is a useful tool to complete the information obtained by DLS and by the two-dimensional images provided by TEM.

In this way, the AFM images of blank and RFB-loaded nanoparticles depicted in Figure 3 confirm the spheroidal shape previously shown by TEM. Moreover, results derived from AFM analysis were expressed as the frequency (\%) of nanoparticles exhibiting a specific height. Thus, blank and RFB-loaded nanoparticles exhibited a similar size, as values of $43 \pm 3 \mathrm{~nm}$ and $33 \pm 1 \mathrm{~nm}$, respectively, were obtained (Figure 4). The smaller nanoparticle height reported by AFM in comparison with the diameters obtained by DLS and TEM corroborates the existence of a spheroidal structure, closer to a disk than to a sphere. This structure further confirms the prevalence of the polymorphic $\alpha$-form of lipids $[27,31]$, as previously mentioned, which has been associated with a high loading capacity and a low tendency to expulse the encapsulated drug from the lipid matrix [27]. 


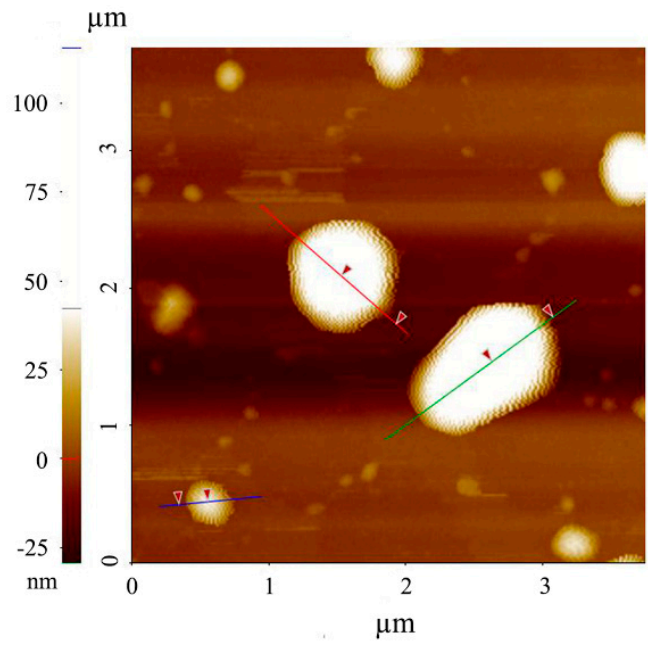

(A)

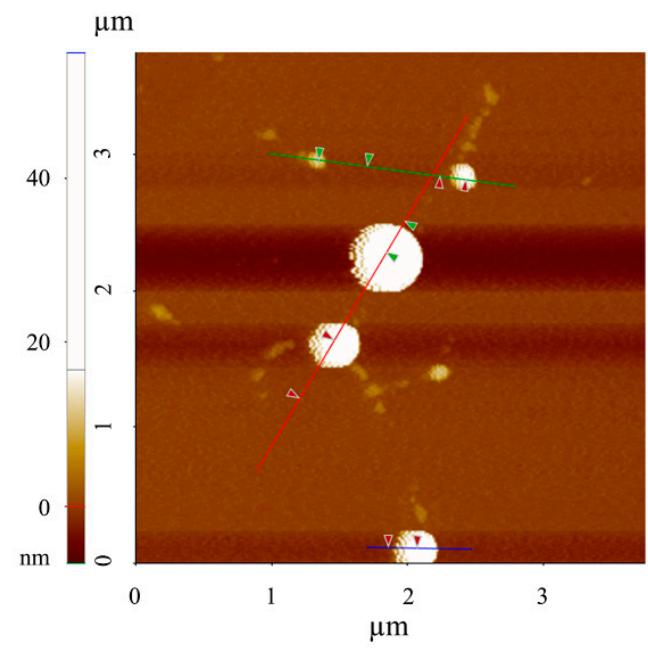

(B)

Figure 3. Atomic force microscopy images of (A) Blank and (B) RFB-loaded NLC.

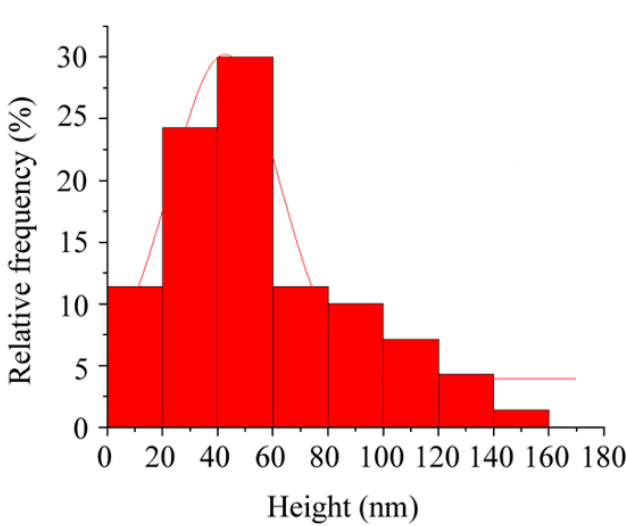

(A)

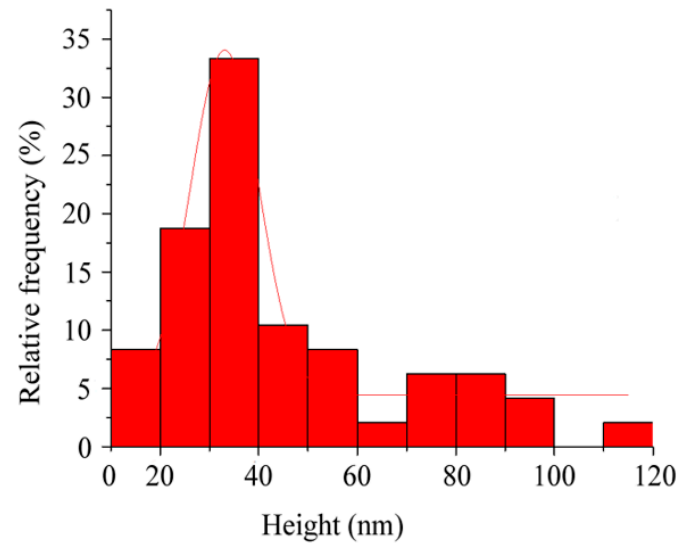

(B)

Figure 4. Particle size and size distribution according to AFM analysis of (A) Blank and (B) RFB-loaded NLC. Results were adjusted to a gaussian distribution.

\subsubsection{In Vitro Release Studies}

Release studies were performed to investigate the ability of NLC to act as RFB reservoirs. This compound is an antimicrobial agent active against widely known Mycobacterium species, including M. leprae, M. tuberculosis, or MAP [8], an infectious agent increasingly related with CD development [3]. Furthermore, RFB has been included in the triple oral anti-mycobacterial regimen currently under evaluation intended to eradicate MAP infection from CD patients [8]. In this way, release from nanoparticles was performed in both simulated intestinal fluid (SIF) and macrophage's lysate, with the aim of analyzing the expected drug release profile in the gut and intracellular environment, respectively. In the drug release study in SIF, the experimental results indicated that the RFB release from NLC in intestinal environment is negligible, since the amount of drug released during the whole assay was not detected by HPLC. Regarding RFB release assay in murine macrophage's lysate, the released drug started to be detectable at $1 \mathrm{~h}$, and increased progressively until $16 \mathrm{~h}$, when the amount of RFB in release medium was found to be quantifiable by HPLC. After $16 \mathrm{~h}, 1.46 \pm 0.47 \mu \mathrm{g}$ of drug were detected in the receptor chamber of Franz diffusion cells, resulting in a release percentage of $0.1 \pm 0.03 \%$ at the end of the experiment.

In physiological conditions, drug release from lipid nanocarriers has been reported to occur, simultaneously, through erosion and diffusion mechanisms [33]. Poor RFB release from NLC obtained 
in the assays is likely to be related with the high lipophilicity of the drug $(\log \mathrm{P}=4.218)$ [34], as well as with the favorable conditions within the nanoparticle due to the high RFB solubility in the lipid matrix, which significantly reduces drug diffusion towards the aqueous release medium [35]. Several authors employed different strategies to overcome these issues associated with the poor in vitro release profile of lipophilic drugs, such as the addition of ethanol [36] or surfactants [37] in the release medium. However, in most cases, these approaches are not representative of the in vivo environment.

Regarding drug release through lipid matrix degradation, it is necessary to consider that it occurs primarily by enzymes, and also through hydrolytic processes, although to a lesser extent [33]. Because of that, analysis of NLC matrix degradation by enzymes present in both intestine and macrophage intracellular environment constitutes an interesting approach. According to the results obtained, NLC matrix can efficiently endure pancreatin activity of SIF, however, it is more affected by enzymes present in macrophage intracellular environment. Despite the higher effectivity of these macrophage enzymes, the amount of drug released from nanoparticles is still low. This slight drug release can be associated with the low enzymatic concentration in macrophage lysate achieved after dilution of cell suspension with Milli- $\mathrm{Q}^{\circledR}$ water. Therefore, as this concentration would obviously be higher inside macrophages in physiological conditions, a greater drug release would also be expected in this case.

Hence, outcomes obtained constitute an interesting proof of concept of the controlled and selective drug release provided by NLC inside macrophages, where MAP has been reported to establish a persisting infection [6].

\subsection{In Vitro Cellular Studies}

\subsubsection{Cell Viability Studies}

SLN and NLC are composed of biodegradable lipids with generally recognised as safe (GRAS) status [38]. However, despite these promising features, further studies are required to support their therapeutic use [18]. For this purpose, cell viability of THP-1 derived macrophages was analysed after NLC treatment.

Figure 5a shows cell viability after treatment with blank and RFB-loaded formulations at several concentrations $(0.3,0.12,0.06$ and $0.03 \mathrm{mg} / \mathrm{mL})$. Besides, cells treated with equivalent RFB concentrations were used as control (Figure $5 b$ ). In general, formulations exhibited a good biocompatibility, leading to cell viabilities $\geq 70 \%$ for concentrations lower than $0.3 \mathrm{mg} / \mathrm{mL}$. Two-way ANOVA $(p<0.05)$ points out a statistically significant effect of treatment (blank NLC or RFB-loaded NLC), NLC concentration, and their interaction on cell viability. 


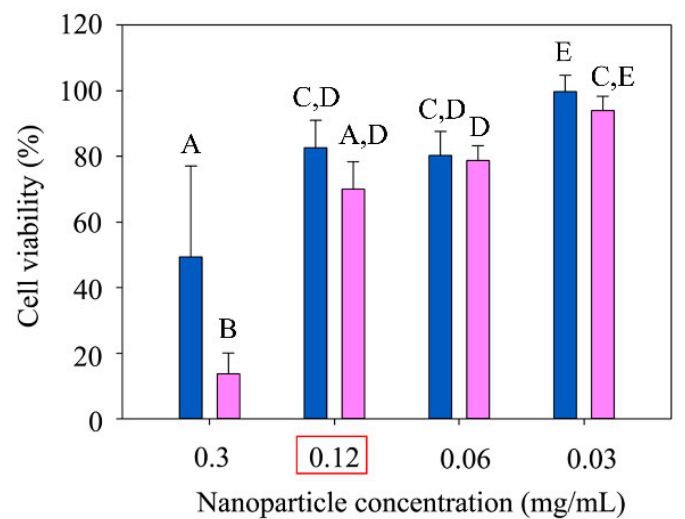

(a)

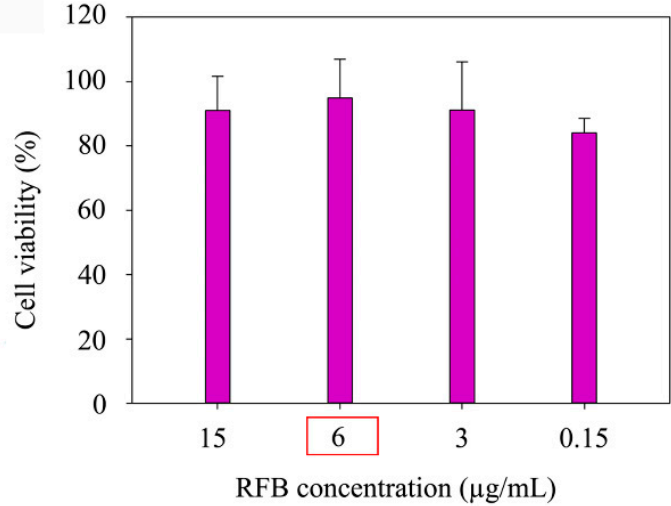

(b)

Figure 5. Cell viability (\%) relative to control with Milli-Q ${ }^{\circledR}$ water of (a) blank NLC formulations (dark blue colour) and RFB-loaded formulations (pink colour), using several nanoparticle concentrations $(0.3,0.12,0.06$ and $0.03 \mathrm{mg} / \mathrm{mL})$. (b) Cell viability (\%) relative to control with DMSO, of RFB solutions in DMSO prepared employing the same drug concentration as present in NLC formulations (purple colour). (A-E characters denote the homogeneous subsets pointed out by the post hoc Tukey's Multiple Comparison Test $(p<0.05)$.

Post hoc Tukey's Multiple Comparison Test $(p<0.05)$ points out a NLC concentration-dependent cytotoxic effect. However, it shows no statistical differences in cell viability for the experiments carried out with RFB-loaded NLC at $0.12 \mathrm{mg} / \mathrm{mL}$ and $0.06 \mathrm{mg} / \mathrm{mL}$, therefore, the concentration $0.12 \mathrm{mg} / \mathrm{mL}$ was selected for further assays.

On the other hand, no significant modifications in cell viability were observed for RFB solutions (Figure 5b) containing equivalent amounts of drug, which implies that the reduction in viability must be mainly attributed to the toxicity of NLC components (oleic acid or emulsifiers), as suggested by several authors [39,40], and not to cytotoxic effects derived from RFB inclusion in the nanocarriers.

To allow the comparison of the cytotoxicity results obtained for RFB-loaded NLC with available data in literature, determination of $\mathrm{IC}_{50}$ was accomplished (Figure 6). The estimation of this value was performed from dose-response curves, where $\mathrm{IC}_{50}$ was defined as the concentration required to induce a $50 \%$ reduction in cell viability, resulting in a value of approximately $0.18 \mathrm{mg} / \mathrm{mL}$. This finding is in line with previously published studies on lipid nanoparticle cytotoxicity, where $\mathrm{IC}_{50}$ was reported to be found mainly in the range of $0.1-1 \mathrm{mg} / \mathrm{mL}$ nanoparticles [18].

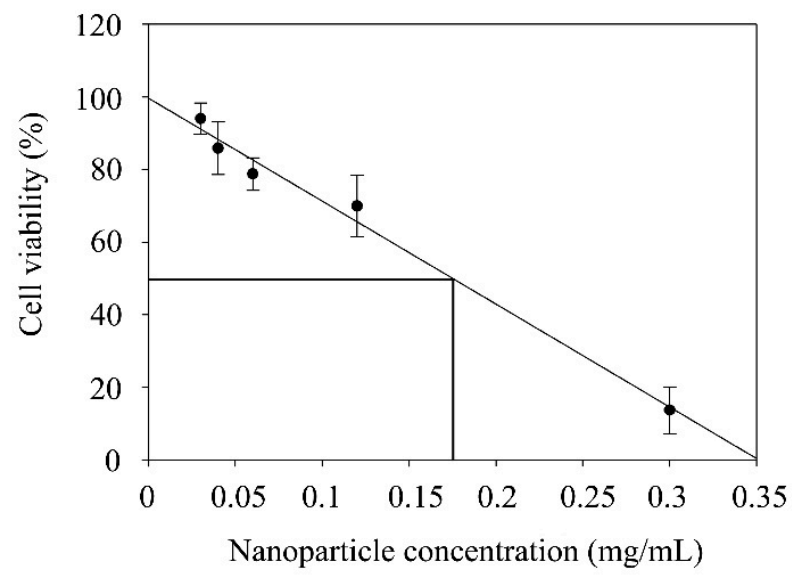

Figure 6. Dose response curve $\left(\mathrm{R}^{2}=0.9881\right)$ obtained from cell viability data at several RFB-loaded NLC concentrations. $\mathrm{IC}_{50}$ was calculated as the concentration of nanoparticles producing a $50 \%$ reduction in cell viability. 
From the results obtained, NLC formulations present a suitable safety profile, similar to previously published works with lipid nanoparticles. Moreover, the highest NLC concentration of all the tested ones, showing an adequate biocompatibility in THP-1 derived macrophages, has been found to be $0.12 \mathrm{mg} / \mathrm{mL}$. A cell viability $\geq 70 \%$ has been reported to be the threshold, according to ISO 10993-5 [41], below which a cytotoxic effect is considered to take place.

\subsubsection{Confocal Microscopy}

Qualitative study of both blank and RFB-loaded NLC internalization by THP-1 derived macrophages was analysed employing a nanoparticle concentration of $0.12 \mathrm{mg} / \mathrm{mL}$, in accordance with the results obtained in the cell viability experiment. Moreover, the selection of this value was based not only on the results obtained in the biocompatibility assay, but also on the drug concentration required to efficiently eradicate the mycobacterial infection.

Regarding this last point, a minimum inhibitory concentration (MIC) ranging from 0.5 to $4 \mu \mathrm{g} / \mathrm{mL}$ has been obtained in vitro for RFB in both human and animal isolated MAP strains. Interestingly, five of six MAP human isolates show a MIC of only $1 \mu \mathrm{g} / \mathrm{mL}$ for this drug [42]. Furthermore, RFB has been reported to slow the multiplication of three virulent strains of Mycobacterium avium complex [43], a group of which MAP is an important member [44], in a model of intracellular infection in human macrophages when a dose of $0.5 \mu \mathrm{g} / \mathrm{mL}$ is employed [43]. Considering that RFB payload in NLC has been proven to reach almost $5 \%$ of the solid content of the formulations, a dose of approximately $6 \mu \mathrm{g} / \mathrm{mL}$ of drug was administered to macrophages. This drug concentration is clearly superior to the value required for RFB MIC, guaranteeing the administration of an effective dose to cells.

As observed in Figure 7, both blank (Figure 7A) and RFB-loaded NLC (Figure 7B) have been efficiently taken up by macrophages, which constitutes a promising start point for the treatment of infections produced by intracellular pathogens such as MAP. Images of separate channels of blank and loaded formulations are shown in Figures S1 and S2, respectively. Furthermore, images of NLC uptake by a macrophages group can be found in Figure S3.

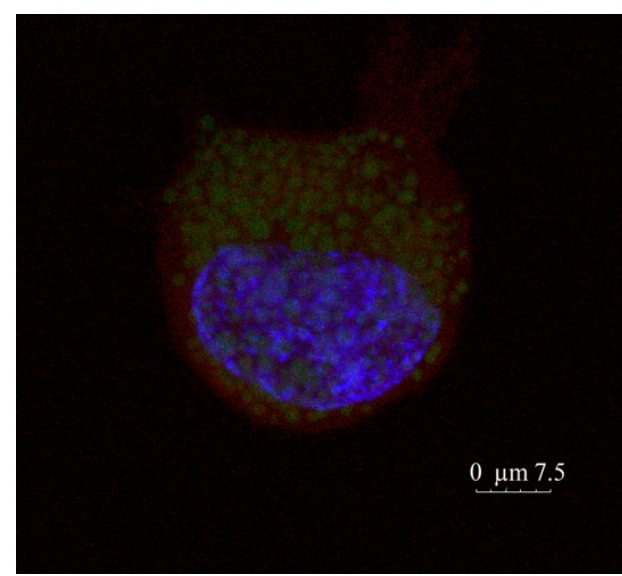

(A)

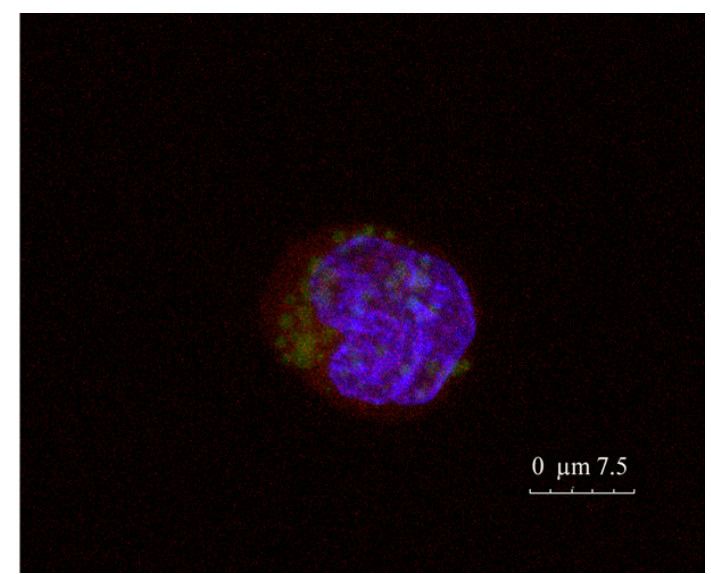

(B)

Figure 7. Confocal microscopy images of (A) Blank and (B) RFB-loaded NLC macrophages uptake. Red, blue, and green colours represent cell cytoplasm (Alexa Fluor ${ }^{\mathrm{TM}} 647$ phalloidin), cell nuclei (DAPI) and NLC formulations (Coumarin 6), respectively.

\subsubsection{Macrophage Uptake Quantification}

Nanoparticle internalization by macrophages was also investigated using a quantitative approach and NLC formulations at $0.12 \mathrm{mg} / \mathrm{mL}$. In this method, blank formulations showed an internalization percentage of $8.33 \pm 1.15 \%$ after $2 \mathrm{~h}$ of exposure. Moreover, a higher internalization percentage, $13.39 \pm 1.44 \%$, was obtained for RFB-loaded NLC. Statistical analysis (one-way ANOVA, $p<0.05$ ) revealed significant differences between the uptake of blank and loaded formulations. This higher 
macrophages uptake reported for loaded formulations might be related to their size $(151 \pm 34 \mathrm{~nm})$, larger than the blank ones $(111 \pm 3 \mathrm{~nm})$, since the uptake of particulate systems by macrophages rises progressively with the particle size increase [45].

In addition, the uptake percentage obtained for RFB-loaded NLC reveals that $13 \%$ of the administered dose $(6 \mu \mathrm{g} / \mathrm{mL}$ or $0.6 \mu \mathrm{g}$ each well) was efficiently taken up by macrophages, which constitutes a total RFB amount of $0.078 \mu \mathrm{g}$ per well. Since each well contains 25.000 cells and human macrophages have a cell volume of approximately $4990 \mu^{3}$ [46], a total cell volume of $1.2475 \times 10^{-4} \mathrm{~mL}$ is expected. Taking together the volumes of internalized drug and the total cell volume estimated, it is reasonable to think that an internalized concentration of $625 \mu \mathrm{g} / \mathrm{mL}$ could be achieved, which exceeds the range of the intracellular MIC previously reported. It is also important to note that colocalization phenomena amongst nanoparticles and mycobacteria have been suggested to occur by means of phagolysosomes fusion [47]. In this way, RFB would not be free in the cytoplasm and hence, it would probably not be the substrate of efflux pumps, which could modify the intracellular drug concentration indicated in this work.

\subsubsection{Nanoparticle Permeation across Caco-2 Cells Monolayers}

Nanoparticle permeation across the intestinal barrier is required to reach intestinal macrophages. Despite some of them being able to extend dendrites into the intestinal lumen, the majority of the macrophages are located below the epithelial monolayer, in the lamina propria [48]. The analysis of nanoparticles permeability across human colon carcinoma cell monolayers (Caco-2) has been reported to establish a good correlation with human in vivo absorption and has been broadly employed to predict drug permeability [24]. The drug concentration in the receptor compartment was estimated from the NLC concentration in this compartment at different times. Results are shown in Figure 8. No NLC permeation across the Caco-2 monolayer occurred during the first $2 \mathrm{~h}$. After, RFB concentration in the receptor compartment increased linearly over time, achieving RFB concentrations of $3.29 \times 10^{-4}$ $0.06 \pm 0.05,0.43 \pm 0.01$ and $0.9 \pm 0.1 \mu \mathrm{g} / \mathrm{mL}$ at $4,6,24$, and $48 \mathrm{~h}$, respectively. In addition, a Papp value of $2.02 \times 10^{-6} \mathrm{~cm} / \mathrm{s}$ was obtained for RFB-NLC formulations. A Papp value of $2 \times 10^{-6} \mathrm{~cm} / \mathrm{s}$ has been reported as the threshold to achieve complete drug absorption in humans [49], therefore, the obtained value for RFB-NLC suggests that they exhibit good permeability across Caco-2 monolayers.

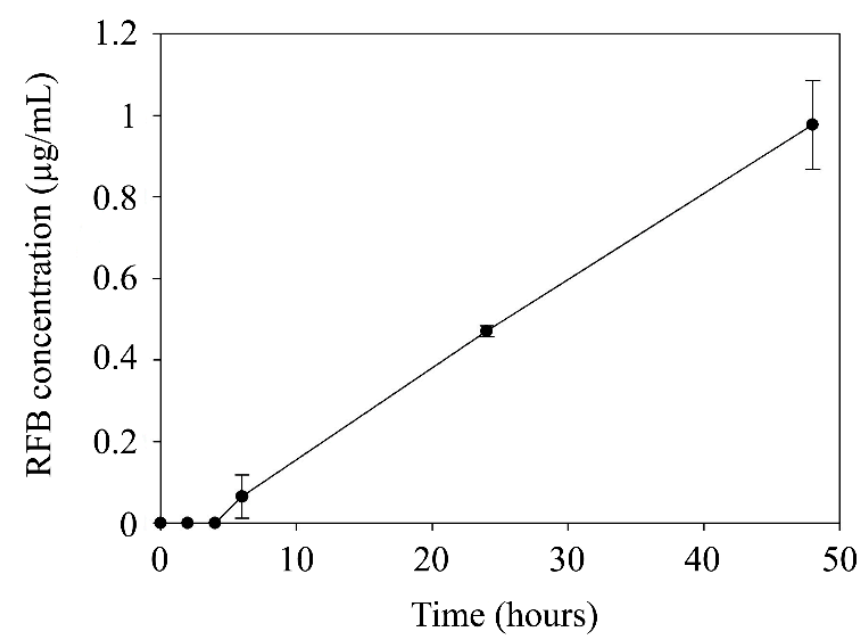

Figure 8. Permeation profile of rifabutin (RFB) loaded in NLC across Caco-2 cell monolayers expressed as a function of drug concentration in the lower compartment in a 48-h time interval.

Besides, the achieved permeability allowed to obtain a drug concentration virtually in range with the previously mentioned MIC reported for RFB just after $24 \mathrm{~h}$ of incubation with the nanocarriers, which is the accurate colonic transit time described for patients with CD [5]. Moreover, the in vivo permeability exhibited by NLC across the intestinal membrane of CD patients is expected to be even 
higher than reflected by this assay. The disruption of the epithelial barrier shown by inflammatory bowel disease patients increases gut permeability and favors nanoparticle passage [5]. In this way, nanoparticles are expected to accumulate preferentially in the intestinal inflamed sites, which are densely infiltrated with macrophages [5], ensuring the administration of an effective drug dose to the infected cells.

\section{Conclusions}

NLC showing a particle size within the nano-range (111 $\pm 3-151 \pm 34 \mathrm{~nm}) ;$ a monodisperse size distribution $(0.22 \pm 0.02-0.23 \pm 0)$, a negative zeta potential $(-24 \pm 2--26 \pm 2 \mathrm{mV})$, and a suitable rifabutin payload $(4.62 \pm 0.33 \%)$ were successfully prepared using a formulation process previously optimized by Artificial Intelligence tools. Formulations exhibited a spheroidal appearance, a good ability to withstand high temperature-related processes and a good safety profile in cellular studies. Moreover, the efficient macrophage uptake of the developed NLC has been demonstrated allowing the obtention of a therapeutic rifabutin concentration after only $2 \mathrm{~h}$ of incubation. This fact, along with the permeation exhibited by NLC across Caco- 2 cell monolayers and their tendency to release the drug in the intracellular environment, guarantee the achievement of an effective rifabutin dose inside the phagocytic cells, where mycobacterium avium paratuberculosis is known to reside. Therefore, rifabutin-loaded NLC constitute a promising tool to improve anti-mycobacterial therapy in Crohn's disease.

Supplementary Materials: The following are available online at http://www.mdpi.com/2079-4991/10/11/2138/s1, Figure S1: Confocal imaging of blank NLC macrophages uptake, Figure S2: Confocal imaging of RFB-loaded NLC macrophages uptake, Figure S3: Confocal imaging of blank NLC uptake by a group of macrophages.

Author Contributions: Conceptualization, H.R., P.D.-R., A.J.A. and M.L.; methodology, H.R., P.D.-R., D.P.G., L.M.D.G. and M.C.; validation, H.R.; formal analysis, H.R. and P.D.-R.; investigation, H.R., P.D.-R., D.P.G., L.M.D.G. and M.C.; resources, C.R.-L., A.J.A. and M.L.; writing-original draft preparation, H.R.; writing-review and editing, P.D.-R., C.R.-L., A.J.A. and M.L.; visualization, H.R.; supervision, C.R.-L., A.J.A. and M.L.; project administration, M.L.; funding acquisition, M.L. All authors have read and agreed to the published version of the manuscript.

Funding: This research was funded by V-A POCTEP Program (0245_IBEROS_1_E) of EU (FEDER), Xunta de Galicia (Competitive Reference Groups, ED431C 2016/008 and ED431C2017/09-FEDER), as well as by Fundação para a Ciência e Tecnologia, Portugal (under iMED.ULisboa project Pest-UID/DTP/04138/2019).

Conflicts of Interest: The authors declare no conflict of interest. The funders had no role in the design of the study; in the collection, analyses, or interpretation of data; in the writing of the manuscript, or in the decision to publish the results. 


\section{Abbreviations}

$\begin{array}{ll}\text { CD } & \text { Crohn's disease } \\ \text { LN } & \text { Lipid nanoparticles } \\ \text { RFB } & \text { Rifabutin } \\ \text { NLC } & \text { Nanostructured lipid carriers } \\ \text { SLN } & \text { Solid lipid nanoparticles } \\ \text { AI } & \text { Artificial intelligence } \\ \text { HPLC } & \text { High performance liquid chromatography } \\ \text { EE } & \text { Encapsulation efficiency } \\ \text { DL } & \text { Drug loading } \\ \text { DLS } & \text { Dynamic light scattering } \\ \text { SIF } & \text { Simulated intestinal fluid } \\ \text { TEM } & \text { Transmission electron microscopy } \\ \text { MAP } & \text { Mycobacterium avium paratuberculosis } \\ \text { TNF } & \text { Tumor necrosis factor } \\ \text { PDI } & \text { Polydispersity index } \\ \text { ZP } & \text { Zeta potential } \\ \text { TEER } & \text { Transepithelial electric resistance } \\ \text { GRAS } & \text { Generally regarded as safe } \\ \text { MIC } & \text { Minimum inhibitory concentration } \\ \text { IC50 } & \text { inhibitory concentration 50 } \\ \text { Papp } & \text { Apparent permeability coefficient } \\ \end{array}$

\section{References}

1. Feuerstein, J.D.; Cheifetz, A.S. Crohn Disease: Epidemiology, Diagnosis, and Management. Mayo Clin. Proc. 2017, 92, 1088-1103. [CrossRef] [PubMed]

2. Cosnes, J.; Gower-Rousseau, C.; Seksik, P.; Cortot, A. Epidemiology and natural history of inflammatory bowel diseases. Gastroenterology 2011, 140, 1785-1794. [CrossRef] [PubMed]

3. Davis, W.C. On deaf ears, Mycobacterium avium paratuberculosis in pathogenesis Crohn's and other diseases. World J. Gastroenterol. 2015, 21, 13411-13417. [CrossRef] [PubMed]

4. Kuenstner, J.T.; Naser, S.; Chamberlin, W.; Borody, T.; Graham, D.Y.; McNees, A.; Hermon-Taylor, J.; Hermon-Taylor, A.; Dow, C.T.; Thayer, W.; et al. The Consensus from the Mycobacterium avium ssp. paratuberculosis (MAP) Conference 2017. Front. Public Health 2017, 5, 208. [CrossRef] [PubMed]

5. Mohan, L.J.; Daly, J.S.; Ryan, B.M.; Ramtoola, Z. The future of nanomedicine in optimising the treatment of inflammatory bowel disease. Scand. J. Gastroenterol. 2019, 54, 18-26. [CrossRef]

6. Murphy, J.T.; Sommer, S.; Kabara, E.A.; Verman, N.; Kuelbs, M.A.; Saama, P.; Halgren, R.; Coussens, P.M. Gene expression profiling of monocyte-derived macrophages following infection with Mycobacterium avium subspecies avium and Mycobacterium avium subspecies paratuberculosis. Physiol. Genom. 2006, 28, 67-75. [CrossRef] [PubMed]

7. NIH. Open Label Efficacy and Safety of Anti-MAP (Mycobacterium avium ssp. paratuberculosis) Therapy in Adult Crohn's Disease (MAPUS2). Available online: https://clinicaltrials.gov/ct2/show/record/NCT03009396? view $=$ record (accessed on 14 July 2020).

8. Savarino, E.; Bertani, L.; Ceccarelli, L.; Bodini, G.; Zingone, F.; Buda, A.; Facchin, S.; Lorenzon, G.; Marchi, S.; Marabotto, E.; et al. Antimicrobial treatment with the fixed-dose antibiotic combination RHB-104 for Mycobacterium avium subspecies paratuberculosis in Crohn's disease: Pharmacological and clinical implications. Expert Opin. Biol. 2019, 19, 79-88. [CrossRef] [PubMed]

9. Honap, S.; Johnston, E.; Agrawal, G.; Al-Hakim, B.; Hermon-Taylor, J.; Sanderson, J. Anti-Mycobacterium paratuberculosis (MAP) therapy for Crohn's disease: An overview and update. Frontline Gastroenterol. 2020. [CrossRef]

10. Blaschke, T.F.; Skinner, M.H. The clinical pharmacokinetics of rifabutin. Clin. Infect. Dis. 1996, 22, S15-S22. [CrossRef] 
11. Zhang, Y.; Feng, J.; McManus, S.A.; Lu, H.D.; Ristroph, K.D.; Cho, E.J.; Dobrijevic, E.L.; Chan, H.K.; Prud'homme, R.K. Design and Solidification of Fast-Releasing Clofazimine Nanoparticles for Treatment of Cryptosporidiosis. Mol. Pharm. 2017, 14, 3480-3488. [CrossRef]

12. Inoue, Y.; Yoshimura, S.; Tozuka, Y.; Moribe, K.; Kumamoto, T.; Ishikawa, T.; Yamamoto, K. Application of ascorbic acid 2-glucoside as a solubilizing agent for clarithromycin: Solubilization and nanoparticle formation. Int. J. Pharm. 2007, 331, 38-45. [CrossRef] [PubMed]

13. Ceci, C.; Graziani, G.; Faraoni, I.; Cacciotti, I. Strategies to Improve Ellagic Acid Bioavailability: From Natural or Semisynthetic Derivatives to Nanotechnological Approaches Based on Innovative Carriers. Nanotechnology 2020, 31, 382001. [CrossRef] [PubMed]

14. Cacciotti, I.; Chronopoulou, L.; Palocci, C.; Amalfitano, A.; Cantiani, M.; Cordaro, M.; Lajolo, C.; Callà, C.; Boninsegna, A.; Lucchetti, D. Controlled release of $18-\beta$-glycyrrhetic acid by nanodelivery systems increases cytotoxicity on oral carcinoma cell line. Nanotechnology 2018, 29, 285101. [CrossRef] [PubMed]

15. Wais, U.; Jackson, A.W.; He, T.; Zhang, H. Nanoformulation and encapsulation approaches for poorly water-soluble drug nanoparticles. Nanoscale 2016, 8, 1746-1769. [CrossRef] [PubMed]

16. Müller, R.H.; Petersen, R.D.; Hommoss, A.; Pardeike, J. Nanostructured lipid carriers (NLC) in cosmetic dermal products. Adv. Drug Deliv. Rev. 2007, 59, 522-530. [CrossRef] [PubMed]

17. Khosa, A.; Reddi, S.; Saha, R.N. Nanostructured lipid carriers for site-specific drug delivery. Biomed. Pharm. 2018, 103, 598-613. [CrossRef]

18. Doktorovova, S.; Souto, E.B.; Silva, A.M. Nanotoxicology applied to solid lipid nanoparticles and nanostructured lipid carriers-A systematic review of in vitro data. Eur. J. Pharm. Biopharm. 2014, 87, 1-18. [CrossRef]

19. Rouco, H.; Diaz-Rodriguez, P.; Rama-Molinos, S.; Remunan-Lopez, C.; Landin, M. Delimiting the knowledge space and the design space of nanostructured lipid carriers through Artificial Intelligence tools. Int. J. Pharm. 2018, 553, 522-530. [CrossRef]

20. Gaspar, M.M.; Cruz, A.; Penha, A.F.; Reymao, J.; Sousa, A.C.; Eleuterio, C.V.; Domingues, S.A.; Fraga, A.G.; Filho, A.L.; Cruz, M.E.; et al. Rifabutin encapsulated in liposomes exhibits increased therapeutic activity in a model of disseminated tuberculosis. Int. J. Antimicrob. Agents 2008, 31, 37-45. [CrossRef]

21. Tominaga, H.; Ishiyama, M.; Ohseto, F.; Sasamoto, K.; Hamamoto, T.; Suzuki, K.; Watanabe, M. A water-soluble tetrazolium salt useful for colorimetric cell viability assay. Anal. Commun. 1999, 36, 47-50. [CrossRef]

22. Ngamwongsatit, P.; Banada, P.P.; Panbangred, W.; Bhunia, A.K. WST-1-based cell cytotoxicity assay as a substitute for MTT-based assay for rapid detection of toxigenic Bacillus species using $\mathrm{CHO}$ cell line. J. Microbiol. Methods 2008, 73, 211-215. [CrossRef]

23. Gaspar, D.P.; Faria, V.; Goncalves, L.M.; Taboada, P.; Remunan-Lopez, C.; Almeida, A.J. Rifabutin-loaded solid lipid nanoparticles for inhaled antitubercular therapy: Physicochemical and in vitro studies. Int. J. Pharm. 2016, 497, 199-209. [CrossRef] [PubMed]

24. Chaves, L.L.; Costa Lima, S.A.; Vieira, A.C.C.; Barreiros, L.; Segundo, M.A.; Ferreira, D.; Sarmento, B.; Reis, S. Nanosystems as modulators of intestinal dapsone and clofazimine delivery. Biomed. Pharm. 2018, 103, 1392-1396. [CrossRef] [PubMed]

25. Gaba, B.; Fazil, M.; Khan, S.; Ali, A.; Baboota, S.; Ali, J. Nanostructured lipid carrier system for topical delivery of terbinafine hydrochloride. Bull. Fac. Pharm. Cairo Univ. 2015, 53, 147-159. [CrossRef]

26. Danaei, M.; Dehghankhold, M.; Ataei, S.; Hasanzadeh Davarani, F.; Javanmard, R.; Dokhani, A.; Khorasani, S.; Mozafari, M.R. Impact of Particle Size and Polydispersity Index on the Clinical Applications of Lipidic Nanocarrier Systems. Pharmaceutics 2018, 10, 57. [CrossRef] [PubMed]

27. Gordillo-Galeano, A.; Mora-Huertas, C.E. Solid lipid nanoparticles and nanostructured lipid carriers: A review emphasizing on particle structure and drug release. Eur. J. Pharm. Biopharm. 2018, 133, 285-308. [CrossRef]

28. Schubert, M.A.; Muller-Goymann, C.C. Characterisation of surface-modified solid lipid nanoparticles (SLN): Influence of lecithin and nonionic emulsifier. Eur. J. Pharm. Biopharm. 2005, 61, 77-86. [CrossRef]

29. Mancini, G.; Lopes, R.M.; Clemente, P.; Raposo, S.; Gonçalves, L.M.D.; Bica, A.; Ribeiro, H.M.; Almeida, A.J. Lecithin and parabens play a crucial role in tripalmitin-based lipid nanoparticle stabilization throughout moist heat sterilization and freeze-drying. Eur. J. Lipid Sci. Technol. 2015, 117, 1947-1959. [CrossRef]

30. Battaglia, L.; Gallarate, M. Lipid nanoparticles: State of the art, new preparation methods and challenges in drug delivery. Expert Opin. Drug Deliv. 2012, 9, 497-508. [CrossRef] 
31. Bunjes, H.; Steiniger, F.; Richter, W. Visualizing the structure of triglyceride nanoparticles in different crystal modifications. Langmuir Acs J. Surf. Colloids 2007, 23, 4005-4011. [CrossRef]

32. Sitterberg, J.; Ozcetin, A.; Ehrhardt, C.; Bakowsky, U. Utilising atomic force microscopy for the characterisation of nanoscale drug delivery systems. Eur. J. Pharm. Biopharm. 2010, 74, 2-13. [CrossRef] [PubMed]

33. Pathak, K.; Keshri, L.; Shah, M. Lipid nanocarriers: Influence of lipids on product development and pharmacokinetics. Crit. Rev. Ther. Drug Carr. Syst. 2011, 28, 357-393. [CrossRef]

34. Global Alliance for TB drug development: Rifabutin. Tuberculosis 2008, 88, 145-147. [CrossRef]

35. Iqbal, N.; Vitorino, C.; Taylor, K.M. How can lipid nanocarriers improve transdermal delivery of olanzapine? Pharm. Dev. Technol. 2017, 22, 587-596. [CrossRef]

36. Li, H.; Zhao, X.; Ma, Y.; Zhai, G.; Li, L.; Lou, H. Enhancement of gastrointestinal absorption of quercetin by solid lipid nanoparticles. J. Control. Release 2009, 133, 238-244. [CrossRef] [PubMed]

37. Das, S.; Ng, W.K.; Kanaujia, P.; Kim, S.; Tan, R.B. Formulation design, preparation and physicochemical characterizations of solid lipid nanoparticles containing a hydrophobic drug: Effects of process variables. Colloids Surf. B Biointerfaces 2011, 88, 483-489. [CrossRef]

38. Lasa-Saracibar, B.; Estella-Hermoso de Mendoza, A.; Guada, M.; Dios-Vieitez, C.; Blanco-Prieto, M.J. Lipid nanoparticles for cancer therapy: State of the art and future prospects. Expert Opin. Drug Deliv. 2012, 9, 1245-1261. [CrossRef]

39. Schöler, N.; Olbrich, C.; Tabatt, K.; Müller, R.; Hahn, H.; Liesenfeld, O. Surfactant, but not the size of solid lipid nanoparticles (SLN) influences viability and cytokine production of macrophages. Int. J. Pharm. 2001, 221, 57-67. [CrossRef]

40. Yin, H.; Too, H.P.; Chow, G.M. The effects of particle size and surface coating on the cytotoxicity of nickel ferrite. Biomaterials 2005, 26, 5818-5826. [CrossRef]

41. ISO. Biological Evaluation of Medical Devices Part 5: Tests for Cytotoxicity: In vitro Methods. In EN ISO 10993-5; ISO: Brussels, Belgium, 2009.

42. Zanetti, S.; Molicotti, P.; Cannas, S.; Ortu, S.; Ahmed, N.; Sechi, L.A. "In vitro" activities of antimycobacterial agents against Mycobacterium avium subsp. paratuberculosis linked to Crohn's disease and paratuberculosis. Ann. Clin. Microbiol. Antimicrob. 2006, 5, 27. [CrossRef]

43. Perronne, C.; Gikas, A.; Truffot-Pernot, C.; Grosset, J.; Pocidalo, J.; Vilde, J. Activities of clarithromycin, sulfisoxazole, and rifabutin against Mycobacterium avium complex multiplication within human macrophages. Antimicrob. Agents Chemother. 1990, 34, 1508-1511. [CrossRef]

44. Bull, T.J.; Sidi-Boumedine, K.; McMinn, E.J.; Stevenson, K.; Pickup, R.; Hermon-Taylor, J. Mycobacterial interspersed repetitive units (MIRU) differentiate Mycobacterium avium subspecies paratuberculosis from other species of the Mycobacterium avium complex. Mol. Cell. Probes 2003, 17, 157-164. [CrossRef]

45. Chono, S.; Tanino, T.; Seki, T.; Morimoto, K. Influence of particle size on drug delivery to rat alveolar macrophages following pulmonary administration of ciprofloxacin incorporated into liposomes. J. Drug Target. 2006, 14, 557-566. [CrossRef] [PubMed]

46. Krombach, F.; Münzing, S.; Allmeling, A.-M.; Gerlach, J.T.; Behr, J.; Dörger, M. Cell size of alveolar macrophages: An interspecies comparison. Environ. Health Perspect. 1997, 105, 1261-1263.

47. Lemmer, Y.; Kalombo, L.; Pietersen, R.D.; Jones, A.T.; Semete-Makokotlela, B.; Van Wyngaardt, S.; Ramalapa, B.; Stoltz, A.C.; Baker, B.; Verschoor, J.A.; et al. Mycolic acids, a promising mycobacterial ligand for targeting of nanoencapsulated drugs in tuberculosis. J. Control. Release 2015, 211, 94-104. [CrossRef] [PubMed] 
48. Bain, C.C.; Mowat, A.M. Intestinal macrophages-specialised adaptation to a unique environment. Eur. J. Immunol. 2011, 41, 2494-2498. [CrossRef] [PubMed]

49. Grès, M.-C.; Julian, B.; Bourrié, M.; Meunier, V.; Roques, C.; Berger, M.; Boulenc, X.; Berger, Y.; Fabre, G. Correlation between oral drug absorption in humans, and apparent drug permeability in TC-7 cells, a human epithelial intestinal cell line: Comparison with the parental Caco-2 cell line. Pharm. Res. 1998, 15, 726-733. [CrossRef]

Publisher's Note: MDPI stays neutral with regard to jurisdictional claims in published maps and institutional affiliations.

(C) 2020 by the authors. Licensee MDPI, Basel, Switzerland. This article is an open access article distributed under the terms and conditions of the Creative Commons Attribution (CC BY) license (http://creativecommons.org/licenses/by/4.0/). 